\title{
Dengue Fever Outbreak in Al-Garrahi District, Al-Hudaydah Governorate, Yemen, 2019
}

Khaled Mohammed Al-Jamrah ${ }^{1}$, BSc, MSc; Abdulkareem Nassar ${ }^{1}$, MPH; Ibrahim Mohathab ${ }^{2}$, BSc; Mohammed Al $\mathrm{Amad}^{1}, \mathrm{MPH}$

${ }^{1}$ Yemen-FETP, Ministry of Public Health and Population, Sana'a, Yemen

${ }^{2}$ Malaria Control Program, Ministry of Public Health and Population, Al-Hudaydah, Yemen

\section{Corresponding Author:}

Khaled Mohammed Al-Jamrah, BSc, MSc

Yemen-FETP

Ministry of Public Health and Population

Alhasabah area

Sana'a, 37970

Yemen

Phone: 967777950053

Email: khjamrah2010@gmail.com

\section{Abstract}

Background: Dengue fever (DF) has re-emerged in Yemen with a higher frequency during the last years. On November 6, 2019, an increased number of suspected DF cases in Al-Garrahi district was reported. On November 7, 2019, a team was sent to investigate.

Objective: This study aims to confirm the existence of an outbreak, describe the outbreak characteristics, and recommend suitable intervention for control.

Methods: A descriptive study was conducted. The World Health Organization case definition was used to identify patients. An active search from house to house, along with entomological investigation and health education, was conducted. A line list was used to collect data. Blood specimens were collected and tested by enzyme-linked immunosorbent assay for dengue IgM. Frequency, percentage, and rates were calculated, and the population from the central statistical organization was used.

Results: A total of 2067 cases met the case definition. Of them, 51\% were males and 32\% were aged $<10$ years. All patients complained of fever, headache, and arthralgia (100\%), followed by myalgia and retro-orbital pain (67\% and 39\%, respectively). The first case patient was in week 41, and the peak was reached with 1058 patients in week 46 . The overall attack rate was 16 of 1000 , significantly higher among patients aged 10 years to $<50$ years and $\geq 50$ years compared with patients aged $<10$ years $(17$ and $19 / 1000$ vs $14 / 1000 ; P<.001)$. Of 20 tested blood samples, $12(60 \%)$ were IgM positive. The house index was $70 \%$, the container index was 50\%, and the Breteau index was 140 . Vector control measures with community participation were intensified in week 46, and patient cases decreased to 140 in week 48.

Conclusions: A dengue outbreak was confirmed in Al-Garrahi district. The spread of infection was facilitated by storing water and the presence of indoor larvae. The findings emphasize the importance of health awareness and community participation for containing DF outbreaks.

(iproc 2022;8(1):e36466) doi: $10.2196 / 36466$

\section{KEYWORDS}

dengue fever; outbreak investigation; Yemen; FETP

\section{Multimedia Appendix 1}

A line-list was used to collect data.

[DOCX File, 14 KB-Multimedia Appendix 1] 


\section{Multimedia Appendix 2}

Epidemic curve of suspected DF cases by day of onset, Al-Garrahi district, Al-Hodiedah governorate, Nov 2019.

[PNG File, 15 KB-Multimedia Appendix 2]

\section{Multimedia Appendix 3}

Distribution of suspected DF cases by age, Al-Garrahi district, Al-Hodiedah governorate, Nov 2019.

[PNG File, 13 KB-Multimedia Appendix 3]

\section{Multimedia Appendix 4}

Distribution of suspected DF cases by gender, Al-Garrahi district, Al-Hodiedah governorate, Nov 2019.

[PNG File, $11 \mathrm{~KB}-$ Multimedia Appendix 4]

\section{Multimedia Appendix 5}

Distribution of suspected DF cases by symptoms, Al-Garrahi district, Al-Hodiedah governorate, Nov 2019.

[PNG File, 20 KB-Multimedia Appendix 5]

\section{Multimedia Appendix 6}

Dengue fever outbreak in Al-Garrahi District, Al-Hudaydah Governorate, Yemen, 2019.

[PPTX File, 2011 KB-Multimedia Appendix 6]

\section{Abbreviations}

DF: dengue fever

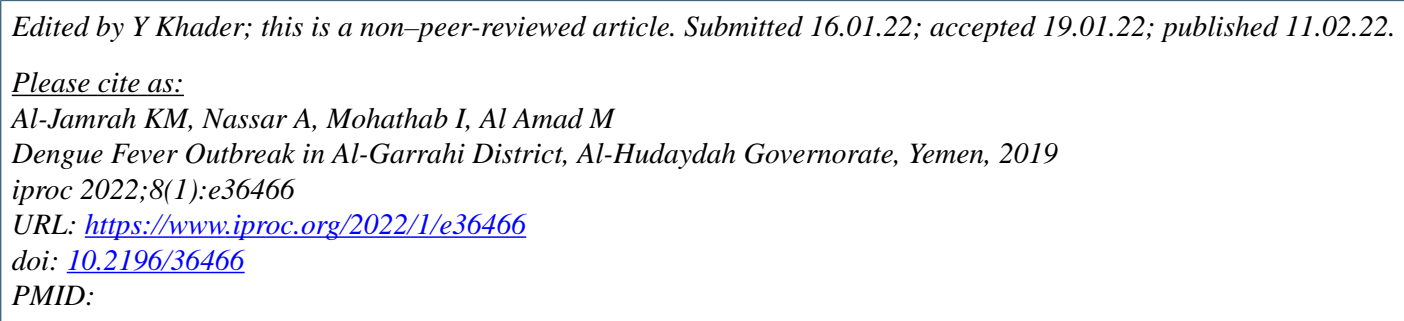

CKhaled Mohammed Al-Jamrah, Abdulkareem Nassar, Ibrahim Mohathab, Mohammed Al Amad. Originally published in Iproceedings (https://www.iproc.org), 11.02.2022. This is an open-access article distributed under the terms of the Creative Commons Attribution License (https://creativecommons.org/licenses/by/4.0/), which permits unrestricted use, distribution, and reproduction in any medium, provided the original work, first published in Iproceedings, is properly cited. The complete bibliographic information, a link to the original publication on https://www.iproc.org/, as well as this copyright and license information must be included. 